\title{
Effect of heat treatment on structure and magnetic properties of $\mathrm{Fe}_{65.5} \mathrm{Cr}_{4} \mathrm{Mo}_{4} \mathrm{Ga}_{4} \mathrm{P}_{12} \mathrm{C}_{5} \mathrm{~B}_{5.5}$ bulk amorphous alloy
}

\author{
*Bratislav Čukić1, Nebojša Mitrović ${ }^{2}$ and Aleksa Maričić ${ }^{2}$ \\ 1. Technical College of Vocational Studies, 32000 Čačak, Serbia; \\ 2. Joint Laboratory for Advanced Materials of SASA, Section for Amorphous Systems, Faculty of Technical Sciences Čačak, University of \\ Kragujevac, 32000 Čačak, Serbia
}

\begin{abstract}
This study deals with the $\mathrm{Fe}_{65.5} \mathrm{Cr}_{4} \mathrm{Mo}_{4} \mathrm{Ga}_{4} \mathrm{P}_{12} \mathrm{C}_{5} \mathrm{~B}_{5.5}$ ferromagnetic bulk amorphous alloy. XRD analysis showed an amorphous structure of the as-cast sample. The same method revealed that, after annealing at $973 \mathrm{~K}$ for $\tau=10 \mathrm{~min}$, the sample displayed a crystalline structure with crystalline phases formed. The crystallization process of the alloy was examined by DTA analysis. It was shown that crystallization took place in the temperature range between $810 \mathrm{~K}$ and $860 \mathrm{~K}$ with the exo-maximum peak temperature at $846 \mathrm{~K}$ with a heating rate of $20 \mathrm{~K} \cdot \mathrm{min}^{-1}$. The method also showed that, at temperatures ranging from $753 \mathrm{~K}$ to $810 \mathrm{~K}$, the alloy exhibited the properties of supercooled liquids. A correlation between heat-induced structural changes and magnetic properties of the alloy was determined by thermomagnetic measurements. Maximum magnetization $\mathrm{M}=3.7 \mathrm{Am}^{2} \cdot \mathrm{kg}^{-1}$ of the alloy was reached after its annealing at $733 \mathrm{~K}$ for $\tau=10 \mathrm{~min}$. Upon annealing, the alloy exhibited a relaxed amorphous structure. Annealing the alloy above the crystallization temperature led to a decrease in bulk magnetization. After annealing at $973 \mathrm{~K}$ for $\tau=10 \mathrm{~min}$, the bulk magnetization of the alloy was $\mathrm{M}^{\prime}=0.45 \mathrm{Am}^{2} \cdot \mathrm{kg}^{-1}$. Accordingly, after crystallization and formation of new compounds, the magnetization of the alloy was decreased by a factor of about 7.7. The strength of the magnetic field applied during the measurements was $H=10 \mathrm{kA} \cdot \mathrm{m}^{-1}$. The samples were tested for changes in the microstructure and hardness of both the amorphous phase and the resulting crystalline phase.
\end{abstract}

Key words: bulk metallic glass; X-ray diffraction analysis; differential thermal analysis; thermomagnetic properties; magnetization; hardness; microstructure
CLC numbers: TG139+.8
Document code: A
Article ID: 1672-6421(2017)01-059-05

$\mathrm{T}$ he development of empirical rules for the synthesis of bulk metallic glasses and methods for the evaluation of increased affinity to amorphization has enabled the production of alloys with a significantly reduced critical cooling rate of several hundred $\mathrm{K} \cdot \mathrm{s}^{-1}$ and increased maximum casting dimensions of about $5-6$ $\mathrm{mm}$ which generate an amorphous structure ${ }^{[1-3]}$.

\section{*Bratislav Čukić}

Male, born in 1963. He is currently a lecturer in the field of Mechanical Engineering Materials and Technologies at the Technical College, Čačak, Serbia. His research area includes amorphous materials in ribbon form obtained by copper mold casting onto a disk, and ferromagnetic powders He has published more than 15 papers in domestic journals and international conference proceedings.

E-mail: bracocukic@gmail.com

Received: 2016-10-24; Accepted: 2016-12-10
Iron-based bulk metallic glasses (BMGs) are of significant scientific interest for their exceptional physical, chemical, mechanical and structural properties ${ }^{[4-6]}$. Moreover, they are commercially very important as they are significantly more cost-effective than other types of bulk amorphous alloys. An extensive range of new alloys of diverse compositions exhibiting a unique combination of physical properties such as high strength, hardness, corrosion resistance and soft magnetic properties have been developed ${ }^{[7-10]}$.

The Fe-Cr-Mo-Ga-P-C-B BMG system has been studied due to the combination of superb soft magnetic characteristics and improved mechanical and corrosion properties compared to other iron-based systems ${ }^{[11-13]}$. In the Fe-Cr-Mo-Ga-P-C-B system, the presence of Mo and $\mathrm{Cr}$ ensures improved casting hardness and good corrosion properties, while the addition of non-metals (C, B, P) contributes to the formation of an amorphous 
structure $^{[14]}$.

Fe-based BMGs have attracted much attention due to their good soft magnetic properties characterized by low coercive force $\left(\mathrm{H}_{\mathrm{c}}<100 \mathrm{~A} \cdot \mathrm{m}^{-1}\right)$, high maximum value of relative magnetic permeability $\left(\mu_{\mathrm{rm}}>10^{4}\right)$, a small area of the hysteresis loop i.e. low magnetic losses, and high hardness ${ }^{[15-17]}$.

The amorphous structure of the material is thermodynamically unstable and highly susceptible to structural relaxation and partial or complete crystallization during thermal treatment. This requires knowledge of the thermal stability of the alloy structure at different temperatures ${ }^{[18-22]}$.

Physical, mechanical and structural properties of BMGs are significantly dependent on thermal or combined thermal and magnetic treatment resulting in materials exhibiting improved properties, as induced by the transformation of the starting amorphous structure.

The present work focuses on the effect of structural changes on the magnetic properties of Fe-based BMGs during and after isothermal annealing at different temperatures. The effect of heat treatment on the structural relaxation, crystallization and magnetic properties of $\mathrm{Fe}_{65.5} \mathrm{Cr}_{4} \mathrm{Mo}_{4} \mathrm{Ga}_{4} \mathrm{P}_{12} \mathrm{C}_{5} \mathrm{~B}_{5.5}$ alloy were examined in order to associate structural changes to the resultant properties of the alloy.

\section{Experimental procedure}

The $\mathrm{Fe}_{65.5} \mathrm{Cr}_{4} \mathrm{Mo}_{4} \mathrm{Ga}_{4} \mathrm{P}_{12} \mathrm{Cr}_{5} \mathrm{~B}_{5.5}$ BMG was cast into copper molds under a protective argon atmosphere to produce cylinders of 1.8 $\mathrm{mm}$ diameter. The amorphous structure of the as-cast sample and structural transformations of the samples after multiple annealing runs were identified by XRD analysis - PHILIPS PW-1050. The thermal stability of the amorphous structure and structural changes during heating at temperatures ranging between $293 \mathrm{~K}$ and $873 \mathrm{~K}$ were tested by the DTA analysis using a SHIMADZU 50 analyzer (Japan) under a protective nitrogen atmosphere.

Thermomagnetic measurements were performed using the modified Faraday method in the temperature range $293 \mathrm{~K}$ to $973 \mathrm{~K}$. The strength of the magnetic field applied during heating and isothermal annealings was $10 \mathrm{kA} \cdot \mathrm{m}^{-1}$. Magnetic force was measured by a SARTORIUS balance having a sensitivity of $10^{-7}$ $\mathrm{N}$. All thermomagnetic measurements were made in an argon atmosphere.

The samples were tested for microstructural changes and hardness. The microstructure of the samples was examined by a POLYVAR MET/REICHERT optical microscope equipped with a LEICA Q $500 \mathrm{MC}$ automatic image analysis device. Hardness was measured by a Reichert device at a load of HV1 $(F=9.81 \mathrm{~N})$.

\section{Results and discussion}

\subsection{Results of XRD analysis}

The diagram in Fig. 1 shows X-ray diffraction patterns of $\mathrm{Fe}_{65.5} \mathrm{Cr}_{4} \mathrm{Mo}_{4} \mathrm{Ga}_{4} \mathrm{P}_{12} \mathrm{C}_{5} \mathrm{~B}_{5.5}$ BMG samples: a) non-annealed sample, b) sample annealed at $T=673 \mathrm{~K}$ for $\tau=10 \mathrm{~min}$,

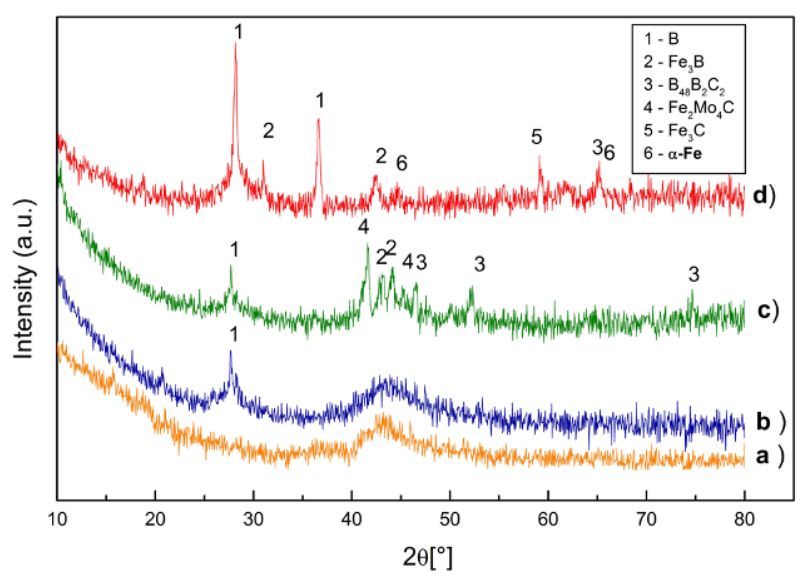

Fig. 1: X-ray diffraction patterns of $\mathrm{Fe}_{65.5} \mathrm{Cr}_{4} \mathrm{Mo}_{4} \mathrm{Ga}_{4} \mathrm{P}_{12} \mathrm{C}_{5} \mathrm{~B}_{5.5}$ BMG samples: a) non-annealed, b) annealed at $T=673 \mathrm{~K}, \mathrm{c}$ ) annealed at $T=873 \mathrm{~K}$ and d) annealed at $T=973 \mathrm{~K}$

c) sample annealed at $T=873 \mathrm{~K}$ for $\tau=10 \mathrm{~min}$, and d) sample annealed at $T=973 \mathrm{~K}$ for $\tau=10 \mathrm{~min}$.

The analysis of the X-ray diffraction patterns presented in Fig. 1. indicates that no pronounced crystalline phases are observed in the X-ray diffraction pattern of the non-annealed sample (Fig. 1a). The X-ray diffraction pattern of the sample annealed at $973 \mathrm{~K}$ for $\tau=10 \mathrm{~min}$ (Fig. 1d) shows intensive diffraction peaks which are due to the crystallization of the amorphous phase and the formation of several iron-based compounds such as $B_{48} B_{2} C_{2}$, $\mathrm{Fe}_{3} \mathrm{~B}$ and $\mathrm{Fe}_{3} \mathrm{C}$. Comparison of the X-ray diffraction patterns in Figs. 1a and 1d for non-annealed and annealed samples, respectively, reveals an amorphous structure of the non-annealed sample.

X-ray diffraction in Figs. 1b and 1c shows that the diffraction pattern of the sample annealed at $673 \mathrm{~K}$ (Fig. 1b) is very similar to that of the non-annealed sample (Fig. 1a). Weak boron reflections observed in the same figure are most likely due to the inhomogeneity of the system during the melting of the pre-alloy. This shows that the sample of the tested alloy annealed up to $673 \mathrm{~K}$ for $\tau=10 \mathrm{~min}$ retains the amorphous structure.

The diffraction pattern of the alloy sample annealed at $873 \mathrm{~K}$ for $\tau=10$ min (Fig. 1c) shows clearly pronounced diffraction peaks induced by the crystallization of the amorphous phase and the formation of the iron-based compounds $\mathrm{Fe}_{3} \mathrm{~B}, \mathrm{Fe}_{2} \mathrm{Mo}_{4} \mathrm{C}$ and $\mathrm{B}_{48} \mathrm{~B}_{2} \mathrm{C}_{2}$. A comparative analysis of the diffraction patterns presented in Figs. 1c and 1d suggests that annealing at $873 \mathrm{~K}$ leads to partial crystallization of the amorphous phase. Annealing the alloy sample at $T=973 \mathrm{~K}$ for $\tau=10$ min results in a multiple increase in diffraction peak intensities (Fig. 1d), with changes in phase relationships in the alloy and the formation of new $\mathrm{Fe}_{3} \mathrm{C}$ compound concurrently occurring.

The decline in magnetization after annealing at temperatures above $793 \mathrm{~K}$ was most likely induced by the increase and change in the proportion of particular phases in the alloy. The analysis of X-ray diffraction patterns for annealed samples indicates that after annealing at $973 \mathrm{~K}$, the $\mathrm{Fe}_{2} \mathrm{Mo}_{4} \mathrm{C}$ phase disappeared and $\mathrm{B}_{48} \mathrm{~B}_{2} \mathrm{C}_{2}$ phase decreased, with $\mathrm{B}$ and $\mathrm{C}$ atoms 
binding $\mathrm{Fe}$ ions into $\mathrm{Fe}_{3} \mathrm{~B}$ and $\mathrm{Fe}_{3} \mathrm{C}$ phases, respectively, which most likely contribute to the decline in magnetization.

\subsection{Results of DTA analysis}

Results of DTA analysis of the non-annealed $\mathrm{Fe}_{65.5} \mathrm{Cr}_{4} \mathrm{Mo}_{4} \mathrm{Ga}_{4} \mathrm{P}_{12} \mathrm{C}_{5} \mathrm{~B}_{5.5}$ BMG sample are presented in Fig. 2.

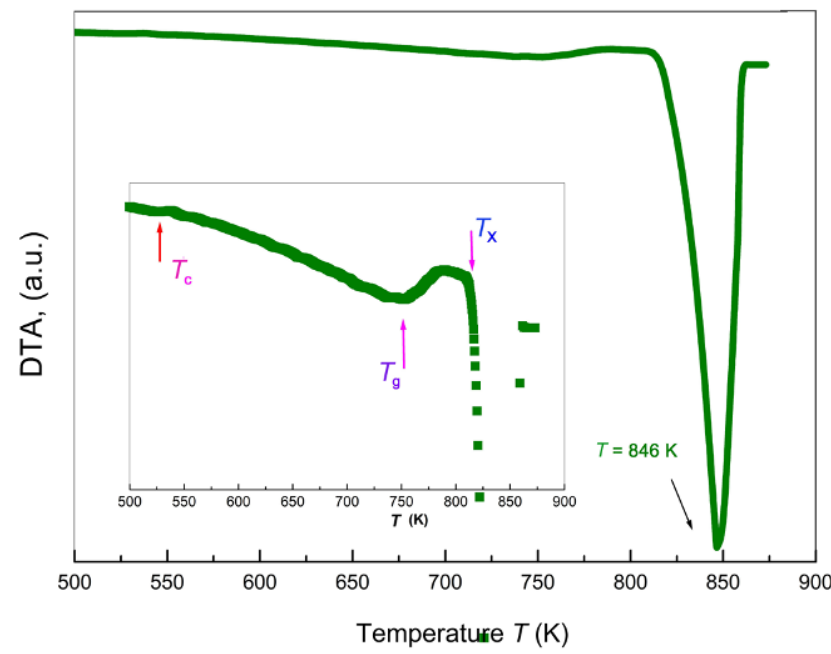

Fig. 2: DTA thermogram of non-annealed $\mathrm{Fe}_{65.5} \mathrm{Cr}_{4} \mathrm{Mo}_{4} \mathrm{Ga}_{4} \mathrm{P}_{12} \mathrm{C}_{5} \mathrm{~B}_{5.5}$ BMG sample with a wide supercooled liquid region $\left(\Delta T_{x}=\right.$ $57 \mathrm{~K}$ ) and Curie temperature $T_{\mathrm{c}}=530 \mathrm{~K}$

The analysis of the thermogram presented in Fig. 2 shows that in the wide temperature range $\Delta T_{\mathrm{x}}$ between glass transition temperature $T_{\mathrm{g}}$ and crystallization onset temperature $T_{\mathrm{x}}\left(\Delta T_{\mathrm{x}}\right.$ $=T_{\mathrm{x}}-T_{\mathrm{g}}=810 \mathrm{~K}-753 \mathrm{~K}=57 \mathrm{~K}$ ) the alloy exhibits the properties of supercooled liquids. The same thermogram shows a small endothermic peak at a temperature $T_{\mathrm{c}}=530 \mathrm{~K}$ corresponding to the Curie temperature. In the temperature range of 810 to $860 \mathrm{~K}$, an intensive exothermic peak is observed, with $T=846$ $\mathrm{K}$ as the temperature of the exo-maximum peak related to the crystallization of the amorphous phase.

\subsection{Results of thermomagnetic measurements}

The results of bulk magnetization measurements of the $\mathrm{Fe}_{65.5} \mathrm{Cr}_{4} \mathrm{Mo}_{4} \mathrm{Ga}_{4} \mathrm{P}_{12} \mathrm{C}_{5} \mathrm{~B}_{5.5}$ BMG during multiple annealings of the same sample are presented in Figs. $3 \mathrm{a}$ and $3 \mathrm{~b}$.

The results of thermomagnetic measurements illustrated in Fig. 3a suggest that, after the first annealing at temperatures up to $403 \mathrm{~K}$, the magnetization of the cooled sample remains unchanged $\mathrm{M}_{1}=1.7 \mathrm{Am}^{2} \cdot \mathrm{kg}^{-1}$. Accordingly, during the first annealing of the sample up to $403 \mathrm{~K}$, there are no structural changes that induce changes in magnetization.

During the second annealing up to $673 \mathrm{~K}$, the magnetization of the sample abruptly increases in the temperature range between $403 \mathrm{~K}$ and $463 \mathrm{~K}$. The abrupt increase in magnetization is due to intense structural relaxation, with the thermal effect leading to the annihilation of structural defects and mechanical microstrain, resulting in the formation of a partially relaxed amorphous structure.

The partially relaxed amorphous structure facilitates the mobility of magnetic domain walls, enhances their orientation
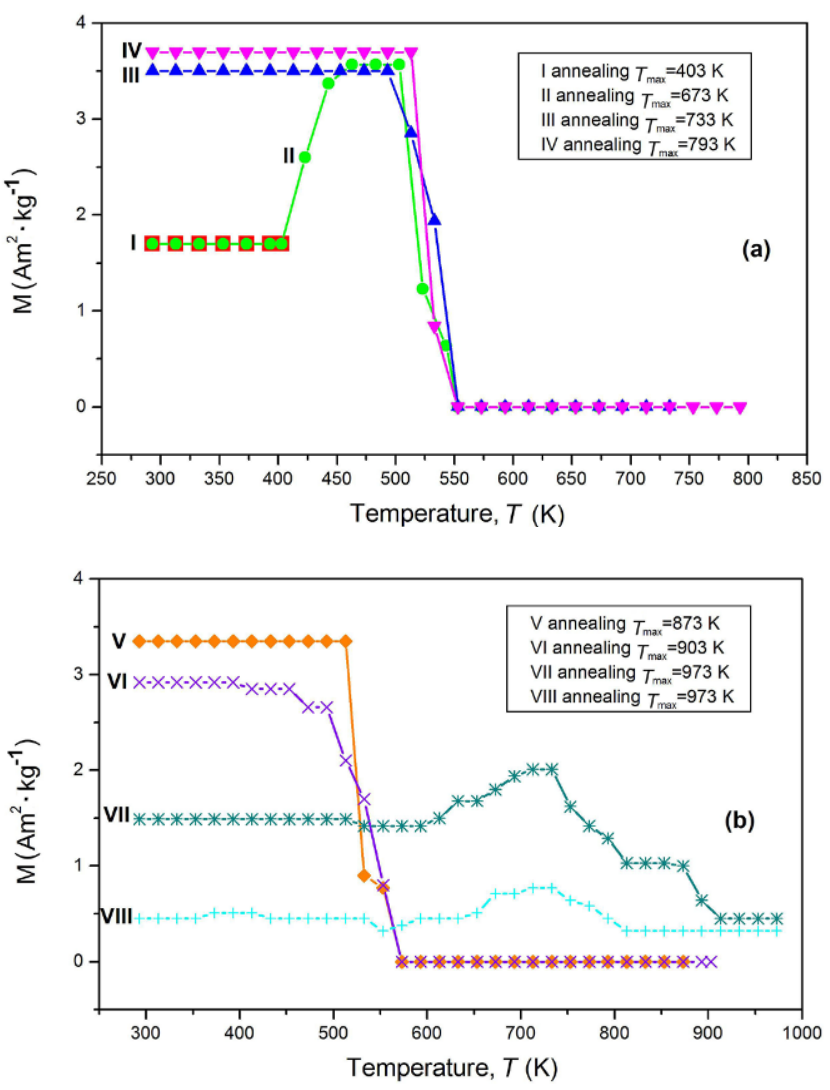

Fig. 3: Magnetization of $\mathrm{Fe}_{65} \mathrm{Cr}_{4} \mathrm{Mo}_{4} \mathrm{Ga}_{4} \mathrm{P}_{12} \mathrm{C}_{5} \mathrm{~B}_{55} \mathrm{BMG}$ as a function of temperature during multiple annealings of the same sample

in the applied magnetic field, and allows an increase in the magnetization of the cooled sample after the second heating up to $673 \mathrm{~K}$ by $105.9 \%$ compared to the starting magnetization of the non-annealed sample, $\mathrm{M}_{2}=3.5 \mathrm{Am}^{2} \cdot \mathrm{kg}^{-1}$. The abrupt decline in magnetization during the second heating at about $530 \mathrm{~K}$ is due to the thermal effect. In ferromagnets, the thermal effect (motion) competes against the orienting field of the exchange interaction striving to direct magnetic moments to align in parallel. At higher temperatures, the thermal effect results in spin ordering destruction and loss of ferromagnetic properties.

After the third annealing up to $733 \mathrm{~K}$, the magnetization of the cooled sample reaches maximum i.e. $\mathrm{M}_{3}=3.7 \mathrm{Am}^{2} \cdot \mathrm{kg}^{-1}$, which is an increase by approx. $117.6 \%$ compared to the magnetization of the as-cast sample. The maximum magnetization value of the cooled sample shows that annealing the sample at $733 \mathrm{~K}$ leads to a fully relaxed amorphous structure.

During the fourth annealing up to $793 \mathrm{~K}$, the magnetization remains constant up to Curie temperature. However, the magnetization of the cooled sample after the fourth annealing at $793 \mathrm{~K}$ is $\mathrm{M}_{4}=3.35 \mathrm{Am}^{2} \cdot \mathrm{kg}^{-1}$, i.e. about $9.5 \%$ lower than the maximum magnetization achieved after the third annealing at $733 \mathrm{~K}$. The decrease in magnetization after the fourth annealing at $793 \mathrm{~K}$ is due to nucleation and increased thermal stability of the structure.

After the fifth annealing at $873 \mathrm{~K}$, there is a substantial decline in magnetization of the cooled sample by about $21 \%$ compared to that of the starting sample, the value being $\mathrm{M}_{5}=$ 
$2.92 \mathrm{Am}^{2} \cdot \mathrm{kg}^{-1}$. This result is completely correlated with XRD results for the sample annealed at $873 \mathrm{~K}$ for $\tau=10 \mathrm{~min}$ (Fig. 1c). Therefore, the decline in the magnetization of the cooled sample after annealing at $873 \mathrm{~K}$ is caused by partial crystallization of the amorphous phase in the alloy and formation of new compounds.

After the sixth annealing run at $903 \mathrm{~K}$, the decline in the magnetization of the cooled sample is $\mathrm{M}_{6}=1.49 \mathrm{Am}^{2} \cdot \mathrm{kg}^{-1}$, i.e. a $59.7 \%$ decline compared to the maximum magnetization of the sample having a fully relaxed amorphous structure.

The maximum decline in the magnetization of the cooled sample occurs after the seventh annealing run at $973 \mathrm{~K}$, its value being $\mathrm{M}_{7}=0.45 \mathrm{Am}^{2} \cdot \mathrm{kg}^{-1}$, i.e. an $87.8 \%$ decline relative to the initial value. This result is likewise completely correlated with the results of XRD analysis of the alloy sample annealed at 973 $\mathrm{K}$ for $\tau=10 \mathrm{~min}$.

The X-ray diffraction pattern in Fig. 1d shows intensive diffraction peaks, thus confirming that the amorphous phase in the alloy has completely transformed into a crystalline state with simultaneous crystal grain growth. Accordingly, after annealing at $973 \mathrm{~K}$, complete thermal stability of the structure is obtained.

The high thermal stability of the crystalline structure and large crystal grains indicate hampered orientation of magnetic domains in the applied magnetic field and, hence, a decrease in the magnetization of the alloy.

The diagram in Fig. 4 shows the magnetization of the cooled sample of the $\mathrm{Fe}_{65.5} \mathrm{Cr}_{4} \mathrm{Mo}_{4} \mathrm{Ga}_{4} \mathrm{P}_{12} \mathrm{C}_{5} \mathrm{~B}_{5.5} \mathrm{BMG}$ as a function of annealing temperature during an annealing time of 10 minutes.

The analysis of the experimental results presented in Fig. 4 indicates that maximum magnetization is reached after annealing at $733 \mathrm{~K}$. Therefore, after annealing at $733 \mathrm{~K}$, the sample exhibits a fully relaxed amorphous structure ensuring maximum mobility of magnetic domain walls and their maximum orientation in the applied magnetic field.

The diagram in Fig. 5 shows the Curie temperature of the $\mathrm{Fe}_{65.5} \mathrm{Cr}_{4} \mathrm{Mo}_{4} \mathrm{Ga}_{4} \mathrm{P}_{12} \mathrm{C}_{5} \mathrm{~B}_{5.5}$ BMG as a function of annealing temperature. The results of measurements presented in Fig. 5. show that structural relaxation (annealing at $733 \mathrm{~K}$ ) causes no appreciable change in the Curie temperature.

The partial crystallization of the alloy (annealing at $793 \mathrm{~K}$

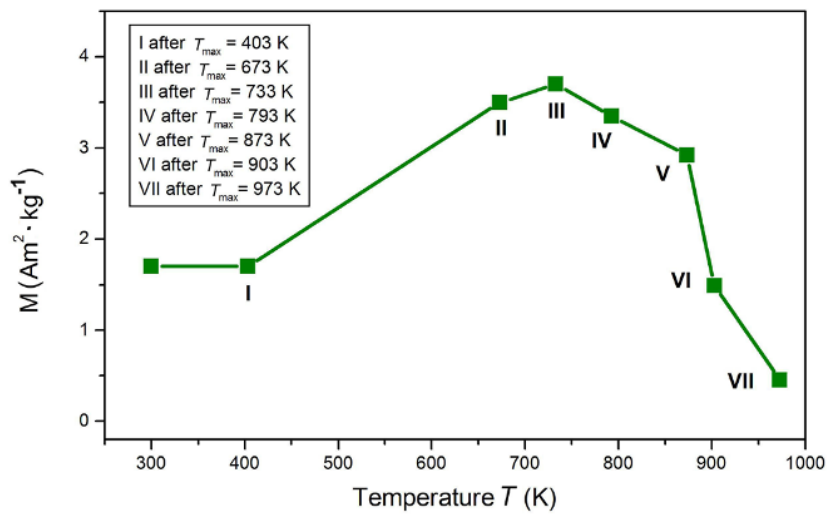

Fig. 4: Magnetization of cooled sample of $\mathrm{Fe}_{65.5} \mathrm{Cr}_{4} \mathrm{Mo}_{4} \mathrm{Ga}_{4} \mathrm{P}_{12} \mathrm{C}_{5} \mathrm{~B}_{5.5}$ BMG as a function of maximum annealing temperature $T_{\max }$

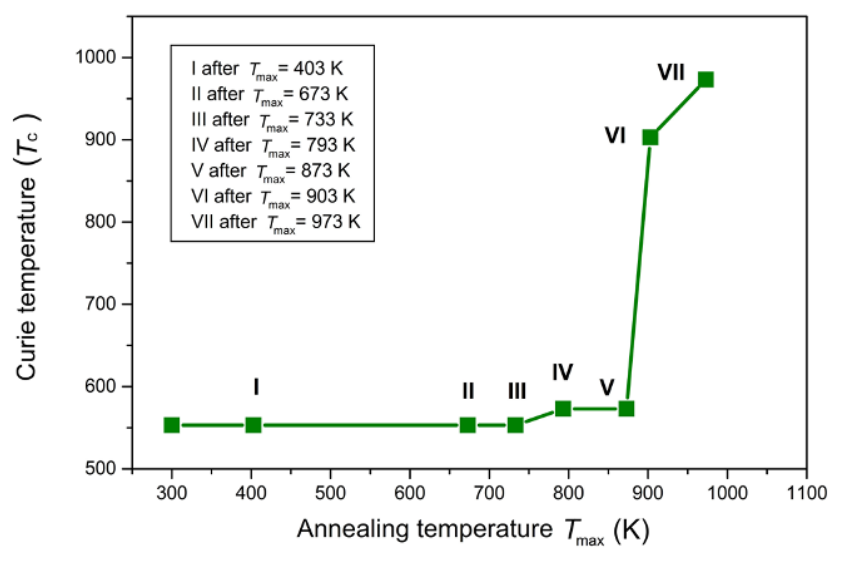

Fig. 5: A change in Curie temperature $T_{\mathrm{c}}$ as a function of maximum annealing temperature $T_{\max }$

and $873 \mathrm{~K}$ ) causes a small increase in the Curie temperature by approx. 5\%. Upon crystallization (annealing at $973 \mathrm{~K}$ ) and formation of new compounds, a high increase in the Curie temperature and an abrupt decline in magnetization occur.

\subsection{Results of mechanical and structural analyses}

Figure 6 presents the microstructures of the tested sample and hardness $\mathrm{HV}_{1}$ measurements. The hardness of the non-annealed sample was about $\mathrm{HV}_{1} \approx 713$. In the sample annealed up to $T_{\max }=973 \mathrm{~K}$, the arrangement of the closer atomic structure occurred in the regions that retained an amorphous state, with
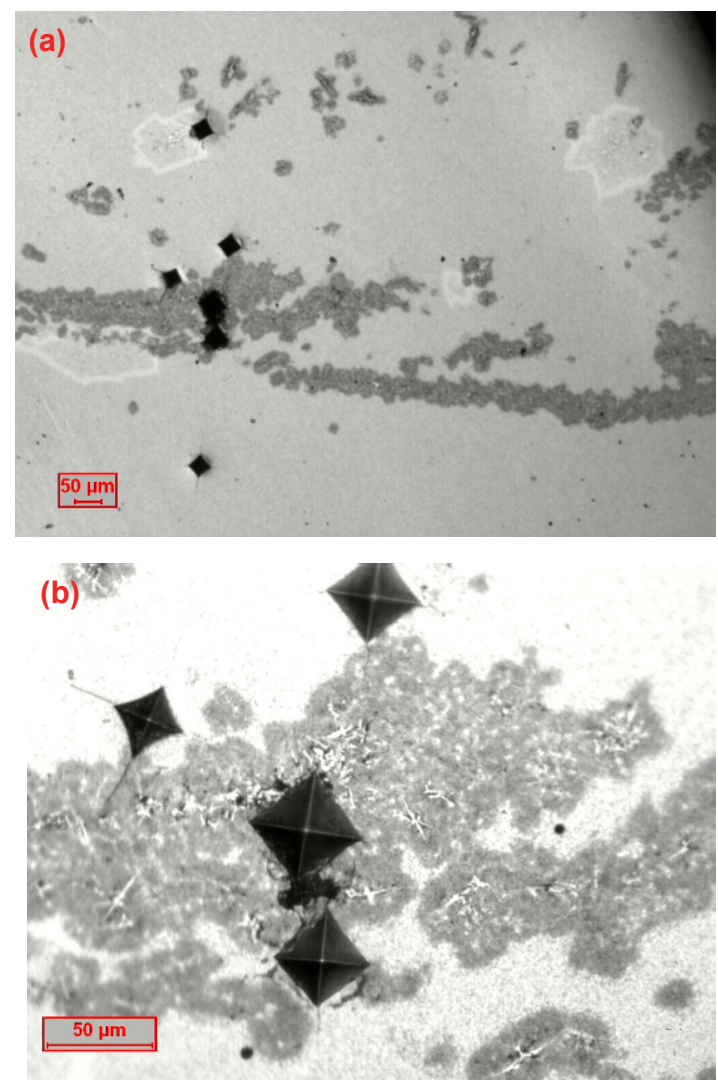

Fig. 6: Microstructures and hardness measurements of mechanical properties of $\mathrm{Fe}_{65.5} \mathrm{Cr}_{4} \mathrm{Mo}_{4} \mathrm{Ga}_{4} \mathrm{P}_{12} \mathrm{C}_{5} \mathrm{~B}_{5.5}$ BMG sample annealed up to $T_{\max }=973 \mathrm{~K}$ 
annealing increasing the hardness of the sample up to about $\mathrm{HV}_{1}$ $\approx 1,119$ (Fig. 6a). In the crystallized regions, hardness values were somewhat lower $\mathrm{HV}_{1} \approx 766$ (Fig. 6b) ${ }^{[23]}$.

\section{Conclusions}

(1) The analysis of XRD results shows that the $\mathrm{Fe}_{65.5} \mathrm{Cr}_{4} \mathrm{Mo}_{4} \mathrm{Ga}_{4} \mathrm{P}_{12} \mathrm{Cr}_{5} \mathrm{~B}_{5.5}$ bulk metallic glass with a diameter of $1.8 \mathrm{~mm}$ produced by copper mold casting has an amorphous structure.

(2) DTA analysis reveals that the alloy in the wide temperature range $\left(\Delta T_{\mathrm{x}}=T_{\mathrm{x}}-T_{\mathrm{g}}=57 \mathrm{~K}\right)$ exhibits the properties of supercooled liquids. The same method shows that the alloy crystallization process takes place in the temperature range $810 \mathrm{~K}$ to $860 \mathrm{~K}$, with the exo-maximum peak temperature at $846 \mathrm{~K}$. The results of thermomagnetic measurements made during multiple isothermal annealings of the same sample at different temperatures for $\tau=10$ min are completely correlated with those of XRD and DTA analyses.

(3) It has been shown that the maximum magnetization of the cooled sample is reached after its annealing at a temperature of $733 \mathrm{~K}$, which is about $20 \mathrm{~K}$ lower than the glass transition temperature. As experimentally determined, intensive structural relaxation takes place in the temperature range of $403 \mathrm{~K}$ to $463 \mathrm{~K}$, leading to an abrupt increase in magnetization by about $105.9 \%$ compared to the magnetization of the as-cast sample.

(4) At temperatures ranging from $463 \mathrm{~K}$ to $573 \mathrm{~K}$, the final stage of structural relaxation occurs, inducing a further increase in magnetization by about $11.7 \%$.

(5) Annealing the sample at temperatures above $733 \mathrm{~K}$ causes a decline in the magnetization of the cooled sample. As shown, annealing at $973 \mathrm{~K}$ causes a maximum decrease in the magnetization of the cooled sample by about $89.2 \%$ compared to that of the as-cast sample, as induced by the formation of new compounds in the alloy with a further increase in the thermal stability of the crystalline structure.

(6) Partial crystallization induced by heating at temperatures above the crystallization temperature causes a significant increase in hardness by about $57 \%$ in the regions that retained an amorphous structure, as opposed to the somewhat lower hardness values in the crystallized regions.

\section{References}

[1] Shen T D, and Schwartz R B. Bulk ferromagnetic glasses prepared by flux melting and water quenching. Appl. Phys. Lett, 1999, 75: 49-51.

[2] Inoue A. Stabilization of metallic supercooled liquid and bulk amorphous alloys. Acta Mater, 2000, 48: 279-306.

[3] Bitoh T, Makino A and Inoue A. Origin of coercivity of Fe-(Al, Ga)(P,C,B,Si,Ge) bulk glassy alloys. Mater. Trans. JIM, 2003, 44: 2020-2024.

[4] Takeuchi A and Inoue A. Classification of bulk metallic glasses by atomic size difference, heat of mixing and period of constituent elements and its application to characterization of the main alloying element. Mater. Trans. JIM, 2005, 46: $2817-$ 2829 .
[5] Amiya $\mathrm{K}$ and Inoue $\mathrm{A}$. Fe-( $\mathrm{Cr}, \mathrm{Mo})-(\mathrm{C}, \mathrm{B})-\mathrm{Tm}$ bulk metallic glasses with high strength and high glass-forming ability. Rev. Adv. Mater. Sci., 2008, 18: 27-29.

[6] Li H X, Wang S L, Yi S, et al. Glass formation and magnetic properties of Fe-C-Si-B-P-(Cr-Al-Co) bulk metallic glasses fabricated using industrial raw materials. J. Magn. Mater., 2009, 321: 2833-2837.

[7] Jian H, Luo W, Tao Sh, et al. Mechanical and magnetic properties of $\left(\mathrm{Fe}_{72} \mathrm{Mo}_{4} \mathrm{~B}_{24}\right)_{100-\mathrm{x}} \mathrm{Tb}_{\mathrm{x}}(\mathrm{x}=4,5,6,7$ at.\%) bulk glassy alloys. J. Alloys Compd., 2010, 505: 315-318.

[8] Guo S F, Li N, Zhang C, et al. Enhancement of plasticity of Febased bulk metallic glass by Ni substitution for Fe. J. Alloys Compd., 2010, 504S: S78-S81.

[9] Bakare M S, Voisey K T, Chokethawal K, et al. Corrosion behavior of crystalline and amorphous forms of the glass forming alloy $\mathrm{Fe}_{43} \mathrm{Cr}_{16} \mathrm{Mo}_{16} \mathrm{C}_{15} \mathrm{~B}_{10}$. J. Alloys Compd., 2012, 527: 210-218.

[10] Suryanarayana C, Inoue A. Iron-based bulk metallic glasses. International Materials Reviews, 2013, 58: 131-166.

[11] Stoica $M$, Eckert J, Roth $S$, et al. Casting and phase transformations of $\mathrm{Fe}_{65,5} \mathrm{Cr}_{4} \mathrm{Mo}_{4} \mathrm{Ga}_{4} \mathrm{P}_{12} \mathrm{C}_{5} \mathrm{~B}_{5,5}$ bulk metallic glass. J. Non-Cryst Mater., 2002, 12: 77-84.

[12] Stoica M, Eckert J, Roth S, et al. Mechanical behavior of $\mathrm{Fe}_{65,5} \mathrm{Cr}_{4} \mathrm{Mo}_{4} \mathrm{Ga}_{4} \mathrm{P}_{12} \mathrm{C}_{5} \mathrm{~B}_{5,5}$ bulk metallic glass. Intermetallics, 2005, 13: 764-769.

[13] Mitrović N, Roth S, Stoica M. Magnetic softening of bulk amorphous FeCrMoGaPCB rods by current annealing technique. J. Alloys Compd., 2007, 434: 618-622.

[14] Mitrović N, Čukić B, Jordović B, et al. Microstructure and Microhardness in Current Annealed $\mathrm{Fe}_{65.5} \mathrm{Cr}_{4} \mathrm{Mo}_{4} \mathrm{Ga}_{4} \mathrm{P}_{12} \mathrm{C}_{5} \mathrm{~B}_{5.5}$ Bulk Metallic Glass. Mater. Sci. Forum, 2007, 555: 521-526.

[15] Stoica M, Degmova J, Roth S, et al. Magnetic Propertis and Phase Transformations of Bulk Amorphous Fe-Based Alloys Obtained By Different Techniques. Mater. Trans., 2002, 43: 1966-1973.

[16] Mitrović N, Roth S, Degmova J, et al. Synthesis, Structure and Properties of Iron-based Glass-forming Metallic Alloys Prepared by Different Processing. Mater. Sci. Forum, 2005, 494: 321-326.

[17] Han J, Wang C, Kou S, et al. Thermal stability, crystallization behavior, Vickers hardness and magnetic properties of $\mathrm{Fe}-\mathrm{Co}$ $\mathrm{Ni}-\mathrm{Cr}$-Mo-C-B-Y bulk metallic glasses. Trans. Nonferrous Met. Soc. China, 2013, 23: 148-155.

[18] Barandiaran J M, Bezanilla J, Davies H A, et al. Magnetic properties of Fe-based bulk ferromagnetic glasses. Sensors and Actuators, 2006, A 129: 50-52.

[19] Li H X, Wang S L, Yi S, et al. Glass formation and magnetic properties of Fe-C-Si-B-P-(Cr-Al-Co) bulk metallic glasses fabricated using industrial raw materials. J. Magn. Mater., 2009, 321: 2833-2837.

[20] Stoica M, Li R, Yavari A R, et al. Thermal stability and magnetic properties of $\mathrm{FeCoBSiNb}$ bulk metallic glasses. J. Alloys Compd., 2010, 504S: S123-S128.

[21] Aykol M, Akdeniz M V, Mekhrabov A O. Solidification behavior, glass forming ability and thermal characteristics of soft magnetic Fe-Co-B-Si-Nb-Cu bulk amorphous alloys. Intermetallics, 2011, 19: 1330-1337.

[22] Han J, Wang C, Kou S, et al. Thermal stability, crystallization behavior, Vickers hardness and magnetic properties of Fe-Co$\mathrm{Ni}-\mathrm{Cr}-\mathrm{Mo}-\mathrm{C}-\mathrm{B}-\mathrm{Y}$ bulk metallic glasses. Trans. Nonferrous Met. Soc. China, 2013, 23: 148-155.

[23] Mitrović N, Čukić B, Jordović B, et al. Microstructure and Microhardness in Current Annealed $\mathrm{Fe}_{65.5} \mathrm{Cr}_{4} \mathrm{Mo}_{4} \mathrm{Ga}_{4} \mathrm{P}_{12} \mathrm{C}_{5} \mathrm{~B}_{5.5}$ Bulk Metallic Glass. Mater. Sci. Forum, 2007, 555: 521-526. 